\title{
The Effects of Major Disruptions on Practice Participation in Facilitation During a Primary Care Quality Improvement Initiative
}

\author{
Jennifer R. Hemler, PhD, Samuel T. Edwards, MD, MPH, Steele Valenzuela, MS, \\ Andrea Baron, MPH, Jennifer D. Hall, MPH, Cynthia K. Perry, PhD, FNP-BC, \\ Bijal A. Balasubramanian, MBBS, PhD, Laura Damschroder, MPH, MS, \\ Leif I. Solberg, MD, Benjamin F. Crabtree, PhD, and Deborah J. Cohen, PhD
}

Background: Disruptions in primary care practices, like ownership change, clinician turnover, and electronic health record system implementation, can stall quality improvement (QI) efforts. However, little is known about the relationship between these disruptions and practice participation in facilitated $Q I$.

Methods: We explore this relationship using data collected from EvidenceNOW in a mixed-methods convergent design. EvidenceNOW was a large-scale facilitation-based QI initiative in small and medium primary care practices. Data included practice surveys, facilitator time logs, site visit field notes, and interviews with facilitators and practices. Using multivariate regression, we examined associations between disruptions during interventions and practice participation in facilitation, measured by in-person facilitator hours in 987 practices. We analyzed qualitative data on $\mathbf{4 0}$ practices that described disruptions. Qualitative and quantitative teams iterated analyses based on each other's emergent findings.

Results: Many practices (51\%) reported experiencing 1 or more disruptions during the 3- to 15-month interventions. Loss of clinicians (31.6\%) was most prevalent. In adjusted analyses, disruptions were not significantly associated with participation in facilitation. Qualitative data revealed that practices that continued active participation were motivated, had some QI infrastructure, and found value in working with their facilitators. Facilitators enabled practice participation by doing EHR-related work for practices, adapting work for available staff, and helping address needs beyond the explicit aims of EvidenceNOW.

Conclusions: Disruptions are prevalent in primary care, but practices can continue participating in QI interventions, particularly when supported by a facilitator. Facilitators may benefit from additional training in approaches for helping practices attenuate the effects of disruptions and adapting strategies to help interventions work to continue building QI capacity. (J Am Board Fam Med 2022;35:124-139.)

Keywords: Family Medicine, Health Personnel, Health Services Research, Primary Health Care, Qualitative Research, Quality Improvement, Surveys and Questionnaires, Workforce

\section{Background}

Primary care medicine in the United States has experienced significant transformations over the past 2 decades due to new federal and state policies

This article was externally peer reviewed.

Submitted 17 May 2021; revised 16 August 2021 and 16 September 2021; accepted 27 September 2021.

From the Department of Family Medicine and Community Health, Research Division, Rutgers Robert Wood Johnson Medical School, New Brunswick, NJ (JRH, BFC); Section of GeneralInternalMedicine, VeteransAffairs(VA)PortlandHealth Care System, Portland, OR (STE); Division of General Internal Medicine and Geriatrics, Oregon Health \& Science University, Portland, OR (STE); Department of Family Medicine, Oregon Health \& Science University, Portland, OR (STE, SV, AB, JDH, DJC); School of Nursing, Oregon Health \& Science University, Portland, OR (CKP); Department of Epidemiology, Human Genetics, andEnvironmentalScience,UTHealthSchoolofPublic Health, Dallas, TX (BAB); Implementation Pathways, LLC and and recommendations, ${ }^{1-4}$ evolving care delivery models and frameworks, ${ }^{5-13}$ technological innovations, ${ }^{6,14}$ and revised payment structures. ${ }^{15-19}$ These changes have increased the need for quality improvement (QI): planning, monitoring, and

VA Center for Clinical Management Research, Ann Arbor, MI (LD); HealthPartners Institute, Minneapolis, MN (LIS).

Funding: This work is supported by Agency for Healthcare Research and Quality grant \#R01HS023940.

Conflict of Interests: The authors report no conflicts of interest in producing and submitting this manuscript for publication. Parts of this early manuscript were presented at the North American Primary Care Research Group, 48 Annual Meeting, November 20, 2020.

Corresponding author: Jennifer R. Hemler, PhD, Rutgers Robert Wood Johnson Medical School, 112 Paterson St., Rm 343, New Brunswick, NJ 08901 (E-mail:hemlerje@ rwjms.rutgers.edu). 
adjusting workflows to new evidence-based practices; using electronic health records (EHRs) to identify and resolve care gaps; and measuring performance concerning clinical guidelines, stakeholder mandates, and incentives. ${ }^{20-25}$ To stay viable in today's landscape, primary care practices need to develop the ability to adapt quickly and embrace continual change. ${ }^{26,27}$

Thus far, making rapid and sustained change has been difficult for primary care practices, ${ }^{28-33}$ particularly small independent practices lacking financial and staff resources. ${ }^{34-39}$ Health system buy-outs, new affiliations, location changes and mergers, and new EHR implementations can disrupt staff, team structures, and workflows. Clinician and staff turnover has also risen in recent years, ${ }^{40-44}$ creating discontinuities in leadership and basic practice operations.

Researchers and QI organizations recognize the need for external support to help practices implement QI within this environment. ${ }^{4-48}$ Practice facilitation (henceforth, facilitation) has arisen to do this. ${ }^{49-57}$ However, facilitators and researchers alike note that practice disruptions like turnover, EHR implementation, and ownership or leadership change can present serious obstacles to practices' engaging in facilitation and QI. ${ }^{39,58-63}$ In particular, pervasive turnover ${ }^{44,64,65}$ is noted as highly disruptive for team building and retaining institutional knowledge, reducing the capacity and motivation of remaining staff to do QI. ${ }^{66}$

Few studies, though, have systematically examined the prevalence and impact of different types of disruptions on practices' participation in facilitated QI. ${ }^{61,67} \mathrm{We}$ examine qualitative and quantitative data from EvidenceNOW, an Agency for Healthcare Research and Quality (AHRQ) national initiative to improve primary care practices' capacity for QI and cardiovascular preventive care delivery, to explore the independent and cumulative effects of disruptions on practices' abilities to participate in facilitation-based QI interventions.

\section{Methods}

\section{Setting}

AHRQ funded 7 Cooperatives across the United States for the EvidenceNOW initiative. Each Cooperative implemented multiple support strategies during an intervention to increase practice capacity for QI and improve cardiovascular preventive care as measured through the "ABCS of heart health": ${ }^{68}$ prescribing Aspirin when appropriate, controlling Blood pressure, managing Cholesterol, and providing Smoking cessation counseling. ${ }^{69}$ Cooperatives collectively enrolled 1721 primary care practices, each enrolling between 208 and 276 sites. ${ }^{70}$ Practices varied in ownership, but most comprised 10 or fewer clinicians (see Table 1). Cooperatives varied in their intervention designs, including use of change models, length of interventions (3 to 15 months), facilitation models, and expected number of facilitator visits; ${ }^{56}$ intervention designs are reported elsewhere, ${ }^{71-76}$ but all used facilitators to support intervention goals. ${ }^{77}$ AHRQ funded our independent national evaluation team, ESCALATES (Evaluating System Change to Advance Learning and Take Evidence to Scale), to assess lessons across Cooperatives.

\section{Data Collection and Analysis}

For this study, we used multiple types and sources of quantitative and qualitative data collected by the Cooperatives and the ESCALATES team in a mixed-methods convergent design. We iteratively conducted mixed-methods analysis: emergent qualitative findings informed hypotheses and variables for quantitative modeling, and quantitative findings provoked additional qualitative analyses.

\section{Quantitative Data Collection}

Cooperatives administered 2 types of surveys. The Practice Survey, answered by 1 practice leader (office manager, practice owner, or lead clinician), included questions about practice size, ownership, location, and past participation in demonstration projects. This survey also asked if the practice had experienced a "major change," providing a list of 6 potential disruptions and a write-in response (see Figure 1).

Cooperatives also administered confidential Practice Member Surveys to multiple employees within each practice. This survey included the 18item Adaptive Reserve questionnaire, assessing leadership and teamwork qualities associated with practice adaptation and resilience. ${ }^{78,79}$

Both surveys were administered at baseline (9/ 2015 to $3 / 2017$ ) to assess the year before the intervention and post-intervention (11/2016 to $12 / 2017)$ to assess the intervention time frame. Survey administration (article, web-based, phone), incentive type (cash, gift card), and incentive amount (\$2-\$75) varied across Cooperatives. 
Figure 1. Practice Survey Question About Disruptions.

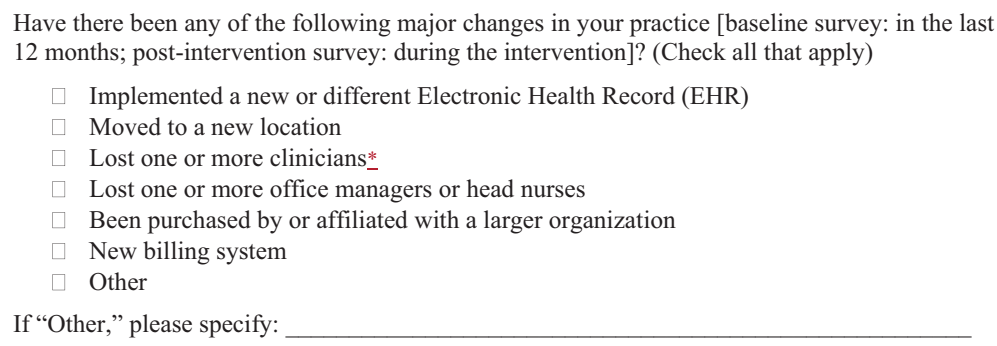

*Practices were instructed to define "clinician" in the survey as an "MD, DO, NP, PA."

Facilitators kept logs across the intervention time frame to record the hours and mode (in-person, phone, or web) they worked with and in the practice.

\section{Quantitative Analysis}

We drew the primary independent variable, occurrence of types of disruptions during the intervention, from the post-intervention Practice Survey. We operationalized participation in facilitation, our outcome variable, as logged total hours of in-person facilitator time per practice. Our thinking was that practices would divert time from facilitation participation to managing disruptions if practice operations were unduly stressed. Covariates of practice size and ownership, geographic location, participation in other demonstration projects, occurrence of disruptions before the intervention, and Adaptive Reserve were obtained from baseline Practice and Practice Member Surveys. We dichotomized practices' Adaptive Reserve scores into the top $25 \%$ (scores of 0.78 and above) versus the bottom $75 \%$, hypothesizing that practices with higher scores would be better able to continue interventions despite disruptions. We included whether or not disruptions occurred before EvidenceNOW to control for ongoing effects of past disruptions.

We used frequencies to describe practice characteristics and participation in facilitation per Cooperative (see Table 1). To explore the relationship between disruptions and participation in facilitation, we performed a series of multivariable regressions, presenting estimated marginal means in hours. To account for Cooperative differences in intervention design and length, we used a generalized estimating equation (GEE) model with a $\gamma$ distribution; this model accounts for clustering by Cooperative to give accurate estimates of the number of hours practices spent in facilitation and association with the selected independent variables.
For disruptions during the intervention, we examined associations between participation in facilitation with each disruption type; with the number of disruption types experienced $(0,1,2$, and $3+$ ); and with having 1 or more types of disruptions. We collapsed "being purchased by or affiliated with a larger organization" $(n=34)$ and "moving to a new location" $(\mathrm{n}=79)$ into 1 category representing organizational disruptions. We collapsed "implemented a new or different EHR" ( $\mathrm{n}=$ $160)$ and "new billing system" $(\mathrm{n}=120)$ into a category representing information system disruptions. We recoded "Other" $(n=139)$ responses into the above categories when applicable. We did not include remaining write-in responses because descriptions were highly variable (see Appendix Table 1). We conducted sensitivity analyses using different definitions of practice participation in facilitation to ensure the reliability of our findings (see Appendix, Table 4). Statistical software included $\mathrm{R}$ version 4.0.0 and Stata version 15.1.

\section{Qualitative Data Collection}

ESCALATES collected interview and observational data throughout EvidenceNOW. During interventions, we shadowed 44 facilitators at 62 practices across the 7 Cooperatives. Cooperatives selected the facilitators and practices for us to observe. We wrote field notes from these site visits and interviewed 41 facilitators about 54 practices. Post-intervention, we sampled practices that had improved in at least 1 ABCS and/or had unique characteristics. We interviewed 66 practice members and 74 facilitators about their work in 110 of these practices. Altogether, the ESCALATES team collected qualitative data on 158 practices. Interviews were audio-recorded and professionally transcribed. Qualitative data were managed in Atlas.ti 7 Windows. 


\section{Qualitative Data Analysis}

A team of analysts (JRH, AB, JDH, CP) read interviews and field notes for each of the 158 practices, identifying practices that had descriptions of the disruptions specified in the Practice Survey. Because medical assistants (MAs) were integral to EvidenceNOW intervention work, we included MA loss as a disruption. This team met weekly to analyze data, reading, and discussing key passages together. We wrote practice summaries and identified patterns in how and why disruptions affected participation in facilitation.

\section{Results}

\section{Practice Characteristics and Reported Disruptions}

Of the 1721 practices enrolled in EvidenceNOW at baseline, 987 (57.4\%) had complete data from baseline and follow-up surveys and between 1 and 90 hours of facilitation participation (see Appendix Figure 1). Practices varied in size and ownership, but most were located in an urban core and had not participated in a demonstration project previously. Practices, on average, participated in 18.2 hours of facilitation ( $\mathrm{SD}=16.7)$. (See Table 1.)

Just over half of practices that completed the surveys reported at least 1 disruption both before and during the interventions (see Table 2), with onethird of these reporting 2 or more disruptions. The most common disruptions were loss of clinician(s) or office manager/head nurse(s), both of which happened more frequently during the intervention than pre-intervention.

In our interview data and field notes, practice members or facilitators described disruptions in 40 of 158 practices. More than half of these practices were described as experiencing multiple types of disruption. Loss of personnel-clinicians, office managers/head nurses, or MAs-were described more often than organizational or information system disruptions.

\section{Disruptions' Effects on Practice Participation in Facilitation}

In quantitative models, practices that reported 1 or more disruptions during their intervention did not differ significantly in participation in facilitation from practices that did not report disruptions. Furthermore, participation in facilitation did not vary significantly by type or number of disruption types reported. (See Table 3; Appendix Table 2.)
Table 1. Practice Characteristics

\begin{tabular}{lc}
\hline Characteristics & \\
\hline Practice Facilitation (Mean hours [SD]) & $18.2(16.7)$ \\
Practice Size/Ownership, n (\%) & \\
Group clinician-owned & $248(25.1)$ \\
Solo clinician-owned & $174(17.6)$ \\
Hospital/HS/HMO & $266(27.0)$ \\
Safety net & $243(24.6)$ \\
Other & $23(2.3)$ \\
Missing & $33(3.3)$ \\
Practice Location, n (\%) & \\
Large town & $152(15.4)$ \\
Rural area & $175(17.7)$ \\
Suburban & $72(7.3)$ \\
Urban & $588(59.6)$ \\
Participation in Other Demonstration & \\
Projects, n (\%) & \\
No & $619(62.7)$ \\
Yes & $316(32.0)$ \\
Missing & $52(5.3)$ \\
Cooperative, n (\%) & \\
Midwest & $196(19.9)$ \\
North Carolina & $136(13.8)$ \\
Northwest & $134(13.6)$ \\
New York City & \\
Oklahoma & \\
Southwest & \\
Virginia & \\
\hline
\end{tabular}

Abbreviations: HS, Health System; HMO, Health Maintenance Organization; SD, standard deviation.

Neither Adaptive Reserve nor prior participation in demonstration projects was associated with participation in facilitation (Appendix Table 3).

Qualitatively, we found that disruptions had differing effects on practices' abilities to participate in facilitation. Some practices decreased or stopped participation in facilitation when disruptions occurred, particularly when they had only 1 person responsible for QI and this person left the practice. However, other practices that experienced similar types or numbers of disruptions continued facilitation. Practices that sustained participation in facilitation through disruptions shared several key attributes: they exhibited high motivation to do the intervention or some degree of preexisting QI infrastructure, and they were able to normalize disruptions as part of the work environment. In addition, practices that found value in their facilitator were likely to continue participating in facilitation despite, and 
Table 2. Disruptive Events Reported by Practices Before and During EvidenceNOW Interventions

\begin{tabular}{lccc}
\hline & $\begin{array}{c}\text { Before } \\
\text { Intervention }\end{array}$ & & $\begin{array}{c}\text { During } \\
\text { Intervention }\end{array}$ \\
$\begin{array}{l}\text { Number of Disruption } \\
\text { Types }\end{array}$ & & $\mathrm{N}(\%)$ \\
0 & $485(49.1)$ & & $476(48.2)$ \\
1 & $329(33.3)$ & & $318(32.2)$ \\
2 & $125(12.7)$ & & $146(14.8)$ \\
$3+$ & $48(4.9)$ & & $47(4.8)$ \\
Disruption Type & $279(28.3)$ & & $318(32.2)$ \\
Lost clinician & $164(16.6)$ & $212(21.5)$ \\
Lost office manager/ & & \\
head nurse & $52(5.3)$ & $59(6.0)$ \\
Organizational* & $142(14.4)$ & $75(7.6)$ \\
\hline Information system $\dagger$ & &
\end{tabular}

*Includes "been purchased by or affiliated with a larger entity"; "moved to a new location".

†'Includes "implemented a new or different electronic health record"; "changed to a new billing system".

sometimes because of, disruptions. Facilitators' approaches to working with practices appeared to influence practices' abilities to maintain participation, as well.

\section{QI Motivation and/or QI Infrastructure}

Practices that continued participating in facilitation during disruptions had specific goals they wanted to achieve through EvidenceNOW. Some of these practices were energized by embarking on QI or felt pressure to catch up on innovations or evidence-based learnings; others had well-established QI routines. Having specific reasons for joining the intervention bolstered participation regardless of QI experience, but practices with QI experience benefited from the stability of set monthly meetings, QI teams, and QI roles. Practices with an engaged QI team, rather than a single QI contact, were less vulnerable to negative turnover effects on participation:

[T]hey're a great clinic to work with, ... [T]hey've been doing a lot of practice transformation.... [T]bey already had QI team put together. They were dedicated to actually work on the things we talked about in between sessions... . At the time we were doing this, they were in the process of losing three [providers] and gaining another three... I I don't really feel like they let that affect their work in this project too much... . [T] he QI team was very dedicated. (Facilitator interview, Cooperative 6)

\section{Normalizing Disruptions}

Some practices accepted disruptions as an inevitable part of practice operations. Practices with consistent staff turnover adjusted to working with capacity gaps. Others realized that they needed to work on QI despite disruptions to avoid penalties or lost incentives, falling behind in evidence-based practices, or patient dissatisfaction. Practices that prioritized QI goals or committed to getting work "done" learned how to work around disruptions. For example, this practice experienced clinician loss and MA turnover during the intervention:

For the satellite office, [turnover is] not anything new. For the main location, it has been something new....

Table 3. Association of Disruptive Events During Intervention with Participation in Facilitation

\begin{tabular}{lcccc}
\hline & Facilitation Participation (hours, 95\% CI) & Difference (hours, 95\% CI) & $P$ value \\
\hline One or More Disruptions Present & Yes & No & & \\
& $14.9(8.3,21.6)$ & $14.5(9.0,20.1)$ & $0.39(-1.18,1.96)$ & 0.630 \\
& Yes & No & & \\
Disruption Type Present & $16.4(8.5,24.3)$ & $15.1(8.9,21.6)$ & $1.28(-1.00,3.56)$ & 0.388 \\
Lost clinician & $15.9(8.7,23.2)$ & $15.3(8.5,22.2)$ & $0.60(-1.51,2.70)$ & 0.786 \\
Lost office manager/head nurse & $14.5(7.1,21.9)$ & $15.5(8.7,22.3)$ & $-1.01(-2.58,0.57)$ & 0.293 \\
Organizational & $14.4(7.1,21.8)$ & $15.6(8.6,22.6)$ & $-1.17(-3.26,0.93)$ & 0.393 \\
Information system & & &
\end{tabular}

Abbreviation: CI, confidence interval.

*Participation in facilitation shown as estimated mean hours, adjusted for events at baseline, practice size/ownership, practice location, participation in other demonstration projects, and Adaptive Reserve. Type III test utilized, testing if all 6 comparisons are equivalent to zero. Statistical significance defined as p-value $<0.05$. 
We had to pull people from this location to belp the other location. That's why it's been a rat race.

Interviewer: Yeab. Do you think that's influenced your ability to work on [EvidenceNOW] at all?

CMA: I don't think so, because it's-things that we have to get done, it just means that you have to learn to multi-task and communicate more with your coworkers to fill in the gaps. (CMA/Health Education Specialist interview, Cooperative 1)

\section{Valued Facilitators}

Facilitators fulfilled a variety of functions for practices. Practices with long-term facilitator relationships appreciated being accountable to someone they trusted. Practices new to QI often felt beholden to facilitators for the skills, tools, information, and support they delivered. Practices that continued participation in facilitation continued receiving these benefits, particularly important to some during times of disruption. For example, 1 clinician-owner who had several staff leave appreciated that his long-term facilitator could help train the new staff: "She works with our staff, and she really gives us a lot of help. It is like we have an extra manager help us" (Clinician Owner Interview, Cooperative 3). Another practice's administrator appreciated their facilitator's persistence despite office manager and staff turnover: "[C]oming in and meeting as a group and then also coming through individually was really good.... [S]he was persistent about being here [and] making sure she made contact with... all the different people here. [H]aving [information] repeated all the time... was really helpful" (Practice Administrator interview, Cooperative 7).

\section{Facilitators' Approaches to Working with Practices During Disruptions}

Facilitators used approaches that encouraged and, in some cases, enabled practices experiencing disruptions to continue their participation in facilitation. For example, facilitators focused on helping practices improve their ABCS performance often did basic EHR work for the practice: facilitators scheduled reminders, produced data reports, called EHR vendors to map out workflows, redesigned templates, and conducted chart audits. Facilitators described doing this kind of work to enable the practice to work on higher-order practice changes:

Turnover [has been] huge.... [T]hey've had actually three different office managers throughout the intervention... Now we have this one office manager that's sort of been with them for a while.... [But] when I try to bring up, "Hey, can you run these reports?" she looks at me like to say, "I really like working with you, but I can't take any more work". ... For now, [I'm running the reports]. ... I'm willing to take a few extra steps for them.... [T]hen when I need them to do something for me, they perform in return... [Slometimes that is also the incentive.... (Facilitator interview, Cooperative 3)

Other facilitators focused on helping practices build QI capacity rather than doing work for the practice; they adapted intervention work to the situation by limiting the scope of PDSAs and aligning goals to help leverage other QI projects. If practices lost personnel, facilitators focused on work those remaining could do. When teams felt overwhelmed, facilitators paused work to give practices time to rebuild capacity. Sometimes, facilitators leveraged disruptions to improve leadership-staff dynamics or streamline workflows. These facilitators viewed progress as a long-term process and adjusted accordingly. For example, this facilitator helped her practice continue participation despite losing a head nurse and MA during the intervention:

The office manager tells the facilitator that they've been doing huddles to see who is high-risk.... [B] ecause of hiring and turnover, the office manager basn't had a chance to change the test group of patients. (This practice started by focusing on 8 bypertensive patients and planned to slowly add more). The facilitator tells her, "That's OK!" The facilitator asks, "So bow are you going to reach out to these patients?" The office manager thinks for a moment and then suggests they do a mailing. The facilitator asks her if she thinks [the business office] could just do five mailings a day, 25 a week. The office manager thinks that sounds doable. They walk through the workflow.... (ESCALATES Site Visit Fiel dnotes, Cooperative 1)

To retain practice engagement, sometimes facilitators helped practices work on projects outside explicit EvidenceNOW goals. For example, facilitators helped practices with incentive programs like Meaningful Use or broader issues like high emergency department (ED) use, transportation needs, food scarcity, substance use disorders, and mental health needs. Facilitators attempted to address practice priorities, sometimes by merging them with EvidenceNOW-specific goals, but often working on these needs in parallel or before their EvidenceNOW agenda. In the following example, the clinician-owner lost a clinician and much of his 
MA staff. The facilitator focused on priorities the clinician outlined:

We worked some on ED utilization and just doing callbacks for patients that had ED visits... some other things that he was really interested in, too, that weren't specifically related to [EvidenceNOW]... around his populations that have behavioral health substance abuse problems.... [S]ome of them have chronic conditions such as bypertension... and be didn't [know] where to refer them. We worked on that as well as kind of an aside, but really tied [that] into providing good comprehensive care for his high-risk patients, too. (Facilitator interview, Cooperative 6)

\section{Discussion}

EvidenceNOW findings affirm that disruptions are a reality across primary care practices, particularly the high turnover of key personnel. Nevertheless, and to our surprise, quantitative analyses revealed little evidence that any particular type of disruption, or even multiple disruptions, affected practices' abilities to participate in facilitation aimed at building QI capacity to achieve cardiovascular care goals. Qualitative analyses may help explain these unexpected results. We found that practices with specific motivations to participate in EvidenceNOW and/ or preexisting QI infrastructure continued participating in facilitation while experiencing disruptions. Accepting disruptions as an inevitable part of their work also seemed to moderate the disruptive impact of disruptions. In addition, facilitators encouraged and, in some cases, enabled practices to continue participating in facilitation by doing EHR-related work, adapting QI work to available staff, and helping them make progress toward patient care goals beyond stated aims of EvidenceNOW. In fact, disruptions may have impelled some practices to continue working with facilitators to receive these highly valued benefits. Facilitators used these approaches to engage practices not experiencing disruptions, as well $;^{80,81}$ however, these approaches may have been especially important for practices experiencing high levels of disruption that needed extra support.

It is also possible that these types of disruption are not as disruptive as they once were. For instance, implementing a new EHR was a paradigm shift a decade ago, but most practices are now upgrading already-existing EHRs; they may know from previous experience what to expect, how to prepare, and where to receive support. ${ }^{59,82}$
Clinician and staff loss may also not be as surprising as it was a decade ago when physician-owned practices were dominant and long tenures the norm. ${ }^{83,84}$ Turnover has increased with increased system acquisitions and mergers, but systems may better compensate for personnel turnover due to their size and resources. ${ }^{61}$ These types of disruptions are no longer surprising or unexpected in the primary care practice landscape.

While practices may have acculturated to these prevalent disruptions, the COVID-19 pandemic, occurring after this research was completed, has raised new research questions about practices' abilities and the strategies needed to quickly adapt or pivot when faced with unprecedented and largescale disruptions. Future research may seek to assess how disruptions happening at different scales or levels (eg, practice, community, region, and beyond), in different domains (eg, personnel, supply delivery), and to different degrees of expectation affect practices' abilities to improve or even maintain their care performance.

This study has a few notable limitations. In the Practice Surveys, we did not capture the number of specific disruption occurrences a practice experienced, only the number of types they experienced. We also did not capture the precise timing of disruptions. Logging disruptions as they occur would enable more sophisticated analyses of how disruptions affect participation in facilitation and for how long. ${ }^{85}$ We suspect that the timing of disruptionsfor example, in the beginning, when facilitators and practices are forming relationships-could affect participation in facilitation. In addition, practices experiencing extreme disruptions may have declined to enroll in EvidenceNOW altogether.

Qualitatively, we performed a secondary analysis of our data. Practices included in our qualitative sample were not selected based on survey reports of disruptions, nor were interview guides designed specifically to explore disruptions. Yet, when asked about intervention implementation and participation challenges, facilitators and/or practice contacts spontaneously described disruptions in 40 of the 158 practices. Our sample may skew toward betterperforming practices in EvidenceNOW, but our findings of influential practice characteristics and facilitator support are likely generalizable across practices.

We call attention to a couple of measurement considerations for future research. We chose 
practice participation in facilitation as our dependent variable because time spent in facilitation indicates an ability to commit to and invest in QI, as time is a precious resource in primary care practices. We operationalized participation as the number of hours of facilitation because this unit of analysis could be standardized across Cooperatives as the "dose" of facilitation that a practice received. We tested several operationalizations of facilitation "dose" (see Appendix Table 4) and found that reports of disruptions were not significantly associated with any of these measures. However, as our qualitative findings show, dose does not capture the complexities of practice engagement, ${ }^{85-87}$ nor does it reflect entirely the amount and content of the intervention work the practice accomplished. ${ }^{85}$ Practice motivation to participate in QI likely influences engagement and participation as well, but a standardized measure was not collected across Cooperatives. Investigating various facets of participation in tandem with dose would help achieve a fuller understanding of the mechanisms leading to sustained practice improvement. We also relied on hours of in-person facilitation, positing that in-person visits require a deeper commitment to the intervention than phone or virtual facilitation; however, this assumption may need to be reevaluated in post-COVID-19 research, as practices continue to adopt and adapt to virtual health care innovations.

It is important to note that our analysis relied on a list of specified disruptions. We suggest more precise and expanded specifications for future studies. For instance, "Lost 1 or more office managers or head nurses" was included as one type of disruption, although the loss of these roles may be experienced quite differently by practices, and each loss should be counted separately to determine disruptive load. Write-in responses and qualitative data suggest that other potential disruptions that should be considered for inclusion in survey response categories include loss of MAs, ${ }^{65,88}$ system-level leadership turnover, ${ }^{89}$ practice expansions, and consolidations. ${ }^{83,84} \mathrm{~A}$ separate and important consideration is turnover in the facilitator role.

Despite these limitations, it is encouraging that practices continued working with facilitators during disruptions, as facilitation is a potential mechanism of practice change. ${ }^{90}$ External facilitators may be particularly poised to navigate the challenges and varying conditions that shape practice QI efforts, guiding practices toward holistic practice change, ${ }^{63,91,92}$ as they are not part of these conditions. Specific training in harnessing disruptions to help practices make necessary but difficult changes may help facilitators build greater practice capacity and get closer to achieving performance improvement goals. However, important questions remain about what facilitator approaches and types of participation in facilitation result in measurable performance improvement. Our study takes one step in that direction by showing that disruptions need not disrupt practice QI time, particularly when practices are supported by skilled facilitators who can help them design their QI efforts to fit their current conditions.

\section{Conclusion}

Disruptions are prevalent within primary care practices in the U.S. Practices can continue facilitation-based QI interventions during disruptions. Disruptions may motivate practices to work with a facilitator, and external facilitators can support practices that may otherwise experience deleterious effects of disruptions. Specific training that addresses how to modify intervention work based on the capacity and knowledge gaps that disruptions can produce will aid facilitators in helping practices make sustained improvements. Future studies should continue to investigate the impacts of different disruptions on different types of interventions and how facilitation can help strengthen practice QI capacity within these conditions.

We are grateful for the advice from Leah Gordon, David Ezekiel, Tom Kottke, Miguel Marino, Rachel Springer, and the EvidenceNOW Cooperatives.

To see this article online, please go to: http://jabfm.org/content/ 35/1/124.full.

\section{References}

1. Institute of Medicine (US) Committee on Quality of Health Care in America. Crossing the Quality Chasm. Washington, DC: National Academies Press (US); 2001.

2. Berwick DM. A user's manual for the IOM's 'Quality Chasm' report. Health Aff (Millwood) 2002;21:80-90.

3. Abrams M, Nuzum R, Mika S, Lawlor G. Realizing health reform's potential. New York: The Commonwealth Fund; 2011.

4. Burke T. The health information technology provisions in the American Recovery and 
Reinvestment Act of 2009: implications for public health policy and practice. Public Health Rep 2010;125:141-5.

5. Wagner EH, Austin BT, Davis C, Hindmarsh M, Schaefer J, Bonomi A. Improving chronic illness care: translating evidence into action. Health Aff (Millwood) 2001;20:64-78.

6. Bodenheimer T. Innovations in primary care in the United States (Primary Care in the United States). BMJ 2003;326:796-800.

7. Solberg LI. Improving medical practice: a conceptual framework. Ann Fam Med 2007;5:251-6.

8. Fisher ES. Building a medical neighborhood for the medical home. N Engl J Med 2008;359:1202-5.

9. Bodenheimer T, Pham HH. Primary care: current problems and proposed solutions. Health Aff (Millwood) 2010;29:799-805.

10. Nutting PA, Crabtree BF, Miller WL, Stange KC, Stewart E, Jaén C. Transforming physician practices to patient-centered medical homes: lessons from the national demonstration project. Health Aff (Millwood) 2011;30:439-45.

11. Sidorov JE. The patient-centered medical home for chronic illness: is it ready for prime time? Health Aff (Millwood) 2008;27:1231-4.

12. Davy C, Bleasel J, Liu H, Tchan M, Ponniah S, Brown A. Effectiveness of chronic care models: opportunities for improving healthcare practice and health outcomes: a systematic review. BMC Health Serv Res 2015;15:1-11.

13. Reynolds R, Dennis S, Hasan I, et al. A systematic review of chronic disease management interventions in primary care. BMC Fam Pract 2018;19:1-13.

14. Jensen RE, Rothrock NE, DeWitt EM, et al. The role of technical advances in the adoption and integration of patient-reported outcomes in clinical care. Med Care 2015;53:153-9.

15. Colla CH, Fisher ES. Beyond PCMHs and accountable care organizations: payment reform that encourages customized care. In: Springer; 2014.

16. Centers for Medicare \& Medicaid Services (CMS). HHS. Medicare Program; Merit-Based Incentive Payment System (MIPS) and Alternative Payment Model (APM) incentive under the physician fee schedule, and criteria for physician-focused payment models. Final rule with comment period 2016;81:77008.

17. Kissam SM, Beil H, Cousart C, Greenwald LM, Lloyd JT. States encouraging value-based payment: lessons from CMS's State Innovation Models Initiative. Milbank Q 2019;97:506-42.

18. Casalino LP. The Medicare access and CHIP Reauthorization Act and the corporate transformation of American medicine. Health Aff (Millwood) 2017;36:865-9.

19. Rosenthal MB, Dudley RA. Pay-for-performance: will the latest payment trend improve care? JAMA 2007;297:740-4.
20. Shortell SM, Waters TM, Clarke KW, Budetti PP. Physicians as double agents: maintaining trust in an era of multiple accountabilities. JAMA 1998;280: 1102-8.

21. Grimshaw J, Eccles M, Thomas R, et al. Toward evidence-based quality improvement. J Gen Intern Med 2006;21:S14-S20.S14.

22. Weisz G, Cambrosio A, Keating P, Knaapen L, Schlich T, Tournay VJ. The emergence of clinical practice guidelines. Milbank Q 2007;85:691-727.

23. Shojania KG, Grimshaw JM. Evidence-based quality improvement: the state of the science. Health Aff (Millwood) 2005;24:138-50.

24. Tricoci P, Allen JM, Kramer JM, Califf RM, Smith SC. Scientific evidence underlying the ACC/AHA clinical practice guidelines. JAMA 2009;301:831-41.

25. Reddy S, Wakerman J, Westhorp G, Herring S. Evaluating impact of clinical guidelines using a realist evaluation framework. J Eval Clin Pract 2015;21:1114-20.

26. Stroebel CK, McDaniel RR, Jr, Crabtree BF, Miller WL, Nutting PA, Stange KC. How complexity science can inform a reflective process for improvement in primary care practices. Jt Comm J Qual Patient Saf 2005;31:438-46.

27. Goldberg DG, Soylu TG, Kitsantas P, Grady VM, Elward K, Nichols LM. Burnout among primary care providers and staff: evaluating the association with practice adaptive reserve and individual behaviors. J Gen Intern Med 2021; 36:1222-8.

28. Cohen D, McDaniel RR, Crabtree BF, et al. A practice change model for quality improvement in primary care practice. J Healthc Manag 2004;49:155.

29. Gupta DM, Boland RJ, Aron DC. The physician's experience of changing clinical practice: a struggle to unlearn. Implement Sci 2017;12:1-11.

30. Grumbach K, Knox M, Huang B, Hammer H, Kivlahan C, Willard-Grace R. A longitudinal study of trends in burnout during primary care transformation. Ann Fam Med 2019;17:S9-S16.

31. Willard-Grace R, Knox M, Huang B, Hammer H, Kivlahan C, Grumbach K. Primary care clinician burnout and engagement association with clinical quality and patient experience. J Am Board Fam Med 2021;34:542-52.

32. Busari JO, Onitilo AA. Fact or Fable: The Truth about Physician Engagement and Burnout. In: Marshfield Clinic; 2020.

33. Crabtree BF, Nutting PA, Miller WL, et al. Primary care practice transformation is hard work: insights from a 15-year developmental program of research. Medical Care 2011;49:S28-S35.

34. Wolfson D, Bernabeo E, Leas B, Sofaer S, Pawlson G, Pillittere D. Quality improvement in small office settings: an examination of successful practices. BMC Fam Pract 2009;10:14. 
35. Meyers DS, Clancy CM. Primary care: too important to fail. Ann Intern Med 2009;150:272-3.

36. Rittenhouse DR, Casalino LP, Shortell SM, et al. Small and medium-size physician practices use few patient-centered medical home processes. Health Aff (Millwood) 2011;30:1575-84.

37. Nutting PA, Crabtree BF, McDaniel RR. Small primary care practices face four hurdles-including a physician-centric mind-set-in becoming medical homes. Health Aff (Millwood) 2012;31: 2417-22.

38. Casalino LP. Technical assistance for primary care practice transformation: free help to perform unpaid labor? Ann Fam Med 2018;16:S12-S15.

39. Noel PH, Romero RL, Robertson M, Parchman ML. Key activities used by community based primary care practices to improve the quality of diabetes care in response to practice facilitation. Qual Prim Care 2014;22:211-9.

40. Dyrbye LN, Shanafelt TD. Physician burnout: a potential threat to successful health care reform. JAMA 2011;305:2009-10.

41. Shanafelt TD, Boone S, Tan L, et al. Burnout and satisfaction with work-life balance among US physicians relative to the general US population. Arch Intern Med 2012;172:1377-85.

42. Shanafelt TD, Hasan O, Dyrbye LN, et al. Changes in burnout and satisfaction with work-life balance in physicians and the general US working population between 2011 and 2014. Mayo Clin Proc 2015;90:1600-13.

43. Edwards ST, Marino M, Balasubramanian BA, et al. Burnout among physicians, advanced practice clinicians and staff in smaller primary care practices. J Gen Intern Med 2018;33:2138-46.

44. Willard-Grace R, Knox M, Huang B, Hammer H, Kivlahan C, Grumbach K. Burnout and health care workforce turnover. Ann Fam Med 2019;17:36-41.

45. Regional Extension Centers (RECs). Department of Health and Human Services. Available at: https:// www.healthit.gov/providersprofessionals/rec-history. Updated November 7, 2018. Accessed August 3, 2020.

46. Quality Improvement Organizations Centers for Medicare and Medicaid Services. Available at: https:// www.cms.gov/Medicare/Quality-Initiatives-PatientAssessment-Instruments/QualityImprovementOrgs/ index.html? redirect=/qualityimprovementorgs/. Updated February 11, 2020. Accessed August 3, 2020.

47. Mold JW, Peterson KA. Primary care practicebased research networks: working at the interface between research and quality improvement. Ann Fam Med 2005;3:S12-S20.

48. Quality Improvement in Primary Care. Agency for Healthcare Research and Quality. Available at: https:/www.ahrq.gov/research/findings/factsheets/ quality/qipc/index.html. Updated April 2020.
49. Practice Facilitation Agency for Healthcare Research and Quality. Patient Centered Medical Home Resource Center Web site. Available at: https:// pcmh.ahrq.gov/page/practice-facilitation. Accessed August 8, 2020.

50. Module 4. Approaches to Quality Improvement. Agency for Healthcare Research and Quality. Available at: https://www.ahrq.gov/ncepcr/tools/pfhandbook/mod4.html. Updated May 2013. Accessed August 3, 2020.

51. IHI Timeline. Institute for Healthcare Improvement. Available at: http://www.ihi.org/about/Documents/ IHI_Timeline_2018.pdf. Updated 2020. Accessed August 3, 2020.

52. Baskerville NB, Liddy C, Hogg W. Systematic review and meta-analysis of practice facilitation within primary care settings. Ann Fam Med 2012;10:63-74.

53. Grumbach $\mathrm{K}$, Bainbridge $\mathrm{E}$, Bodenheimer $\mathrm{T}$. Facilitating improvement in primary care: the promise of practice coaching. Issue Brief (Commonw Fund) 2012;15:1-14.

54. Knox L, Taylor EF, Geonnotti K, et al. Developing and running a primary care practice facilitation program: a how-to guide. Mathematica Policy Research; 2011.

55. Phillips RL, Cohen DJ, Kaufman A, Dickinson WP, Cykert S. Facilitating Practice Transformation in Frontline Health Care. In: Annals Family Med; 2019.

56. Sweeney SM, Hemler JR, Baron AN, et al. Dedicated workforce required to support largescale practice improvement. J Am Board Fam Med 2020;33:230-9.

57. Wang A, Pollack T, Kadziel LA, et al. Impact of practice facilitation in primary care on chronic disease care processes and outcomes: a systematic review. J Gen Intern Med 2018;33:1968-77.

58. Howard J, Shaw EK, Clark E, Crabtree BF. Up close and (inter)personal: insights from a primary care practice's efforts to improve office relationships over time, 2003-2009. Qual Manag Health Care 2011;20:49-61.

59. Goetz DG, Kuzel AJ, Feng LB, DeShazo JP, Love LE. EHRs in primary care practices: benefits, challenges, and successful strategies. Am J Managed Care 2012;18:e48-54-e54.

60. Kadu MK, Stolee P. Facilitators and barriers of implementing the chronic care model in primary care: a systematic review. BMC Fam Pract 2015;16:12.

61. Mold JW, Walsh M, Chou AF, Homco JB. The alarming rate of major disruptive events in primary care practices in Oklahoma. Ann Fam Med 2018; 16:S52-S57.

62. Olmos-Ochoa TT, Ganz DA, Barnard JM, Penney LS, Chawla N. Sustaining effective quality improvement: building capacity for resilience in the practice facilitator workforce. BMJ Qual Saf 2019;28:1016-20. 
63. Russell G, Lane R, Parker S, Preventive Evidence into Practice (PEP) Partnership Group, et al. Preventive evidence into practice: what factors matter in a facilitation intervention to prevent vascular disease in family practice? BMC Fam Pract 2019; 20:113.

64. Ruhe M, Gotler RS, Goodwin MA, Stange KC. Physician and staff turnover in community primary care practice. J Ambul Care Manage 2004;27:242-8.

65. Friedman JL, Neutze D. The financial cost of medical assistant turnover in an academic family medicine center. J Am Board Fam Med 2020;33:426-30.

66. Baron AN, Hemler JR, Sweeney SM, et al. Effects of practice turnover on primary care quality improvement implementation. Am J Med Qual 2020;35:16-22.

67. Parchman ML, Noel PH, Culler SD, et al. A randomized trial of practice facilitation to improve the delivery of chronic illness care in primary care: initial and sustained effects. Implement Sci 2013;8.

68. Division for Heart Disease and Stroke Prevention. Million Hearts ${ }^{(\mathrm{R})}$ Center for Disease Control and Prevention. Available at: https://millionhearts.hhs. gov/data-reports/factsheets/ABCS.html. Updated July 13, 2020. Accessed October 4, 2020.

69. EvidenceNOW: Evaluation Measures. Agency for Healthcare Research and Quality. Available at: https://www.ahrq.gov/evidencenow/research-results/ research/methods/measures.html. Updated August 2018. Accessed August 9, 2020.

70. Cooperatives. Available at: https://www.ahrq.gov/ evidencenow/projects/heart-health/about/index.html. Updated May 2021. Accessed August 9, 2020.

71. About EvidenceNOW: Background and Stories from the Field. Agency for Healthcare Research and Quality. Available at: https://www.ahrq. gov/evidencenow/about/index.html. Updated May 2019. Accessed August 8, 2020.

72. Ciolino JD, Jackson KL, Liss DT, et al. Design of healthy hearts in the heartland (H3): a practicerandomized, comparative effectiveness study. Contemp Clin Trials 2018;71:47-54.

73. Shelley DR, Ogedegbe G, Anane S, et al. Testing the use of practice facilitation in a cluster randomized stepped-wedge design trial to improve adherence to cardiovascular disease prevention guidelines: HealthyHearts NYC. Implement Sci 2015;11:88.

74. Weiner BJ, Pignone MP, DuBard CA, et al. Advancing heart health in North Carolina primary care: the Heart Health NOW study protocol. Implement Sci 2015;10:160.

75. Parchman ML, Fagnan LJ, Dorr DA, et al. Study protocol for "Healthy Hearts Northwest": a $2 \times 2$ randomized factorial trial to build quality improvement capacity in primary care. Implement Sci 2016;11:138.
76. Chou AF, Homco JB, Nagykaldi Z, et al. Disseminating, implementing, and evaluating patientcentered outcomes to improve cardiovascular care using a stepped-wedge design: healthy hearts for Oklahoma. BMC Health Serv Res 2018;18:404.

77. Perry CK, Damschroder LJ, Hemler JR, Woodson TT, Ono SS, Cohen DJ. Specifying and comparing implementation strategies across seven large implementation interventions: a practical application of theory. Implement Sci 2019; 14:32.

78. Nutting PA, Crabtree BF, Miller WL, Stewart EE, Stange KC, Jaén CR. Journey to the patient-centered medical home: a qualitative analysis of the experiences of practices in the National Demonstration Project. Ann Fam Med 2010;8 Suppl 1:S45-56; S92.

79. Miller WL, Crabtree BF, Nutting PA, Stange KC, Jaen CR. Primary care practice development: a relationship-centered approach. Ann Fam Med 2010;8 Suppl 1:S68-79; S92.

80. Nguyen AM, Cuthel A, Padgett DK, et al. How practice facilitation strategies differ by practice context. J Gen Intern Med 2020;35:824-31.

81. Hemler JR, Hall JD, Cholan RA, et al. Practice facilitator strategies for addressing electronic health record data challenges for quality improvement: EvidenceNOW. J Am Board Fam Med 2018;31: 398-409.

82. Ryan MS, Shih SC, Winther CH, Wang JJ. Does it get easier to use an EHR? Report from an urban regional extension center. J Gen Intern Med 2014;29:1341-8.

83. Welch WP, Cuellar AE, Stearns SC, Bindman AB. Proportion of physicians in large group practices continued to grow in 2009-11. Health Aff (Millwood) 2013;32:1659-66.

84. Muhlestein DB, Smith NJ. Physician consolidation: rapid movement from small to large group practices, 2013-15. Health Aff (Millwood) 2016;35: 1638-42.

85. Ye J, Zhang R, Bannon JE, et al. Identifying practice facilitation delays and barriers in primary care quality improvement: a report from Evidence NOW.J Am Board Fam Med 2020;33:655-64.

86. Berry CA, Nguyen AM, Cuthel AM, et al. Measuring implementation strategy fidelity in HealthyHearts NYC: a complex intervention using practice facilitation in primary care. Am J Med Qual 2021;36:270-6.

87. Halladay JR, Weiner BJ, Kim JI, et al. Practice level factors associated with enhanced engagement with practice facilitators: findings from the Heart Health Now study. BMC Health Serv Res 2020;20:1-11.

88. Ferrante JM, Shaw EK, Bayly JE, et al. Barriers and facilitators to expanding roles of medical assistants 
in Patient-Centered Medical Homes (PCMHs). J Am Board Fam Med 2018;31:226-35.

89. Mosadeghrad AM, Ferdosi M, Afshar H, HosseiniNejhad SM. The impact of top management turnover on quality management implementation. Med Arch 2013;67:134-40.

90. Balasubramanian BC, Marino M, Springer R, et al. Capacity for Practice Change, Quality Improvement, and Facilitation to Improve Cardiovascular Preventive Care in Primary Care. 48th Annual Proceedings of the North American Primary Care Research Group; Nov 22-4, 2020; Virtual Meeting.

91. Cohen DJ, Crabtree BF, Etz RS, et al. Fidelity versus flexibility: translating evidence-based research into practice. Am J Prev Med 2008;35: S381-89.

92. Bosch M, Van Der Weijden T, Wensing M, Grol R. Tailoring quality improvement interventions to identified barriers: a multiple case analysis. J Eval Clin Pract 2007;13:161-8. 


\section{Appendix}

Appendix Table 1. Descriptions of “Other” Responses to Post-Intervention Practice Survey Question About Disruptions

\begin{tabular}{|c|c|c|c|}
\hline $\begin{array}{l}\text { "Other" Write-in Responses as } \\
\text { Categorized }\end{array}$ & $\begin{array}{c}\text { Baseline } \\
\text { Survey } \\
\text { (n) }\end{array}$ & $\begin{array}{c}\text { Post- } \\
\text { Intervention } \\
\text { Survey (n) }\end{array}$ & Methodological Treatment \\
\hline $\begin{array}{l}\text { Implemented a new or } \\
\text { different EHR }\end{array}$ & 2 & 0 & Recoded to existing question response \\
\hline Lost one or more clinicians & 2 & 3 & Recoded to existing question response \\
\hline $\begin{array}{l}\text { Lost one or more office } \\
\text { managers or head nurses }\end{array}$ & 0 & 1 & Recoded to existing question response \\
\hline Moved to a new location & 0 & 2 & Recoded to existing question response \\
\hline New billing system & 2 & 2 & Recoded to existing question response \\
\hline Ownership change & 1 & 1 & Recoded to existing question response \\
\hline New staff & 24 & 41 & $\begin{array}{l}\text { Excluded because of varied and ambiguous nature of "staff" and lack } \\
\text { of clarity if new staff were additions or replacements to existing staff }\end{array}$ \\
\hline Lost staff & 2 & 23 & Excluded because of varied and ambiguous nature of "staff" \\
\hline $\begin{array}{l}\text { New EHR features and EHR } \\
\text { challenges }\end{array}$ & 5 & 6 & Excluded because of small $n$ \\
\hline $\begin{array}{l}\text { Practice expansion/merger not } \\
\text { involving ownership change }\end{array}$ & 11 & 10 & $\begin{array}{l}\text { Excluded because of small } \mathrm{n} \text {; unclear if these are the same as existing } \\
\text { question response }\end{array}$ \\
\hline Practice/site closed & 0 & 1 & Excluded because of small $n$ \\
\hline Miscellaneous & 15 & 17 & Excluded because of small $\mathrm{n}$ and heterogeneity of responses \\
\hline $\begin{array}{l}\text { Total responses excluded from } \\
\text { analysis }\end{array}$ & 64 & 106 & \\
\hline
\end{tabular}

Abbreviation: EHR, electronic health record.

Appendix Figure 1. Variation in facilitation hours by practice

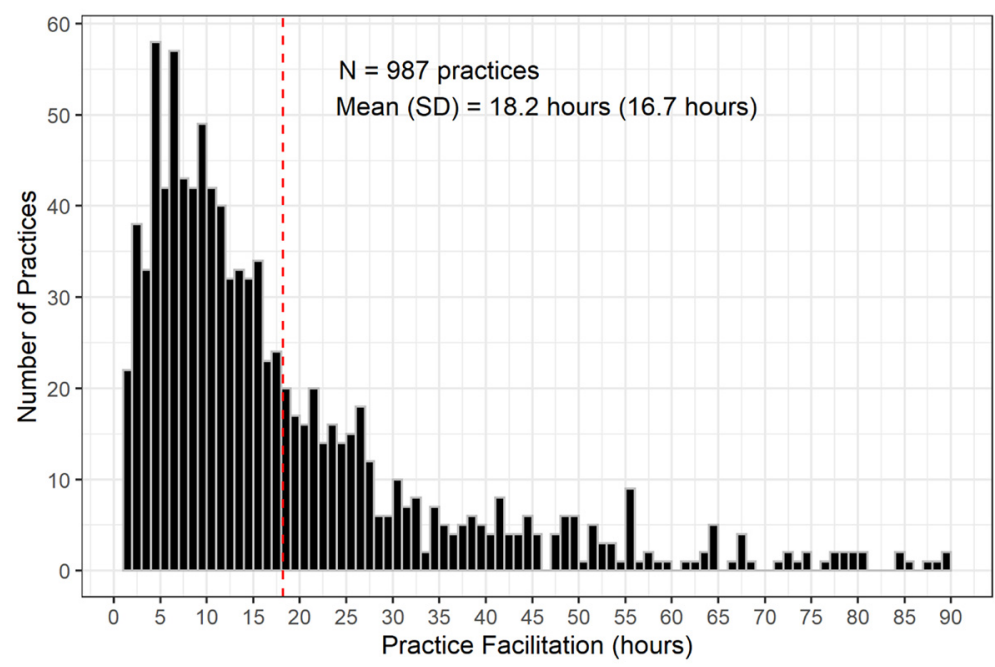




\section{Methods for Appendix Tables 2-4}

We reported rates (exponentiated log-coefficients) and 95\% asymptotic confidence intervals (CI). Postestimation of the model yielded estimated marginal means in hours, stratified by 1 or more disruptions versus no disruptions and difference in hours.
95\% CIs were reported for all 3 outcomes (see Appendix Figure 1). Equal weight was assumed to calculate the estimated marginal means. To account for missing data, we implemented multiple imputation by chained equations, which determined the stability of model estimates (See Appendix Table 2).

Appendix Table 2. Estimated Marginal Hours and Difference in Hours (95\% CI) of Participation in Practice Facilitation by Occurrence of Disruption*

\begin{tabular}{|c|c|c|c|c|}
\hline & & & Difference & $P$ value \\
\hline Disruption Types & No & Yes & & \\
\hline Lost clinician & $15.1(8.9,21.6)$ & $16.4(8.5,24.3)$ & $1.28(-1.00,3.56)$ & 0.388 \\
\hline Lost office manager & $15.3(8.5,22.2)$ & $15.9(8.7,23.2)$ & $0.60(-1.51,2.70)$ & 0.786 \\
\hline Purchased/new affiliation/new location & $15.5(8.7,22.3)$ & $14.5(7.1,21.9)$ & $-1.01(-2.58,0.57)$ & 0.293 \\
\hline \multirow[t]{2}{*}{ New EHR or billing software } & $15.6(8.6,22.6)$ & $14.4(7.1,21.8)$ & $-1.17(-3.26,0.93)$ & 0.393 \\
\hline & 0 events & $1+$ events & & \\
\hline One or More Disruptions & $14.5(9.0,20.1)$ & $14.9(8.3,21.6)$ & $0.39(-1.18,1.96)$ & 0.630 \\
\hline \multirow[t]{12}{*}{ Number of Disruptions ${ }^{\dagger}$} & 0 events & 1 event & & \\
\hline & $15.2(8.9,21.5)$ & $15.5(7.7,23.3)$ & $0.32(-1.93,2.58)$ & 0.983 \\
\hline & 0 events & 2 events & & \\
\hline & $15.2(8.9,21.5)$ & $15.7(8.8,22.7)$ & $0.57(-2.35,3.50)$ & 0.958 \\
\hline & 0 events & $3+$ events & & \\
\hline & $15.2(8.9,21.5)$ & $15.2(8.3,22.2)$ & $0.07(-1.93,2.07)$ & 1.000 \\
\hline & 1 event & 2 events & & \\
\hline & $15.5(7.7,23.3)$ & $15.7(8.8,22.7)$ & $0.25(-2.72,3.22)$ & 0.996 \\
\hline & 1 event & $3+$ events & & \\
\hline & $15.5(7.7,23.3)$ & $15.2(8.3,22.2)$ & $-0.26(-2.00,1.48)$ & 0.981 \\
\hline & 2 events & $3+$ events & & \\
\hline & $15.7(8.8,22.7)$ & $15.2(8.3,22.2)$ & $-0.51(-2.82,1.81)$ & 0.943 \\
\hline
\end{tabular}

Abbreviation: CI, confidence interval; EHR, electronic health record.

*Estimated marginal hours are adjusted over the levels of the following variables: baseline disruptions, practice size ownership, practice location, other demonstration projects, and Adaptive Reserve.

${ }^{\dagger}$ Difference not included for all 6 comparisons. Also, Type III test utilized, testing if all 6 comparisons are equivalent to zero. 
Appendix Table 3. Association of Disruptions During Intervention with Participation in Practice Facilitation: Complete Model, with Imputed and Non-Imputed Results.*

\begin{tabular}{|c|c|c|}
\hline & Estimate (95\% CI) & Imputed Estimates (95\% CI) \\
\hline Intercept & $17.76(13.04,24.20)$ & $17.52(12.50,24.56)$ \\
\hline \multicolumn{3}{|l|}{ Events During Intervention } \\
\hline 0 events & Reference & Reference \\
\hline $1+$ event & $1.03(0.93,1.13)$ & $1.03(0.92,1.15)$ \\
\hline \multicolumn{3}{|l|}{ Events Before Intervention } \\
\hline 0 events & Reference & Reference \\
\hline $1+$ event before intervention & $1.12(1.03,1.22)$ & $1.12(1.03,1.22)$ \\
\hline \multicolumn{3}{|l|}{ Practice Size/Ownership } \\
\hline Group clinician-owned & Reference & Reference \\
\hline Solo clinician-owned & $0.92(0.76,1.12)$ & $0.92(0.76,1.12)$ \\
\hline Hospital/HS/HMO & $0.83(0.71,0.97)$ & $0.84(0.71,0.98)$ \\
\hline Safety net & $0.77(0.54,1.09)$ & $0.77(0.53,1.12)$ \\
\hline Other & $0.74(0.63,0.87)$ & $0.75(0.62,0.90)$ \\
\hline Missing & $0.90(0.68,1.19)$ & - \\
\hline \multicolumn{3}{|l|}{ Practice Location } \\
\hline Large town & Reference & Reference \\
\hline Rural area & $0.96(0.84,1.11)$ & $0.96(0.83,1.12)$ \\
\hline Suburban & $0.73(0.54,0.97)$ & $0.73(0.53,0.99)$ \\
\hline Urban & $1.10(0.79,1.54)$ & $1.10(0.77,1.58)$ \\
\hline \multicolumn{3}{|l|}{ Participate in Other Initiatives } \\
\hline No & Reference & Reference \\
\hline Yes & $0.99(0.87,1.11)$ & $0.99(0.88,1.13)$ \\
\hline Missing & $0.99(0.80,1.23)$ & - \\
\hline \multicolumn{3}{|l|}{ Adaptive Reserve } \\
\hline Low & Reference & Reference \\
\hline High & $0.99(0.89,1.10)$ & $1.00(0.89,1.12)$ \\
\hline Missing & $0.87(0.78,0.97)$ & - \\
\hline
\end{tabular}

Abbreviations: CI, confidence interval; HMO, Health Maintenance Organization; HS, Health System.

* Reference groups (the intercept) include zero follow-up disruptions, zero baseline disruptions, group clinician-owned, large town, no other demonstration projects, and low Adaptive Reserve. 
Appendix Table 4. Alternative Definitions of Participation in Practice Facilitation: Summary and Association with Any Disruption

\begin{tabular}{|c|c|c|c|}
\hline Name & Definition & Summary & $\begin{array}{c}\text { Association With Practice } \\
\text { Event* }(95 \% \text { CI) }\end{array}$ \\
\hline $\begin{array}{l}\text { Consistency of Facilitation } \\
\text { Visits, Mean (SD) }\end{array}$ & $\begin{array}{l}\text { Months during intervention } \\
\text { period with an in-person PF } \\
\text { visit }\end{array}$ & $7.61(3.22)$ & $0.86(0.59,1.31)$ \\
\hline $\begin{array}{l}\text { Length of Facilitation Visit, } \\
\text { Mean (SD) }\end{array}$ & $\begin{array}{l}\text { Total hours of facilitation/total } \\
\text { number of in-person PF visits }\end{array}$ & $1.63(0.89)$ & $1.00(0.94,1.08)$ \\
\hline \multirow[t]{5}{*}{ Dose Categories, N (\%) } & & & $0.94(0.74,1.18)$ \\
\hline & Low: $<10$ hours & $384(38.9)$ & \\
\hline & $\begin{array}{l}\text { Short: } \geq 10-<50 \text { hours, } \\
\quad<10 \text { months }\end{array}$ & $188(19.0)$ & \\
\hline & $\begin{array}{l}\text { Consistent: } \geq 10-<50 \text { hours, } \\
\quad \geq 10 \text { months }\end{array}$ & $351(35.6)$ & \\
\hline & High: $\geq 50$ hours & $64(6.5)$ & \\
\hline
\end{tabular}

Abbreviations: CI, confidence interval; PF, practice facilitation; SD, standard deviation.

*For the participation in practice facilitation outcomes, consistency of practice facilitation and length of practice facilitation visit, a Poisson regression and Gamma regression models were implemented, exploring the effect of any disruption against no disruptions. For dose categories, we used a multinomial logistic regression. Incident rate/odds ratios (exponentiated coefficients) and $95 \%$ CIs were reported.

For months with an in-person encounter, we see a $14 \%$ decrease in practice facilitation if a practice had a disruption versus no disruptions. For length of practice facilitation, we see no effect if a practice had a disruption versus no disruptions. For the pooled dose, there is a $6 \%$ decrease in the odds of a disruption occurring for a Low, Short, or Consistent dose versus a High dose. 